Pacific Journal of Mathematics

EMBEDDING ASYMPTOTICALLY STABLE DYNAMICAL
SYSTEMS INTO RADIAL FLOWS IN $l_{2}$ 


\title{
EMBEDDING ASYMPTOTICALLY STABLE DYNAMICAL SYSTEMS INTO RADIAL FLOWS IN $l_{2}$
}

\author{
ROGER C. MCCANN
}

\begin{abstract}
A dynamical system $\Pi$ on a separable metric space, which has a globally asymptotically stable critical point $p$, can be embedded into a radial flow $\rho$ on $l_{2}$ if and only if $p$ is uniformaly asymptotically stable. Moreover, if $\Pi$ can be embedded into $\rho$, then there is a locally compact subset $Y$ of $l_{2}$ such that $\Pi$ can be embedded into $\rho$ restricted to $Y$.
\end{abstract}

In [1] the author showed that a dynamical system on a locally compact phase space, which has a globally asymptically stable critical point, can be embedded into the radial flow on $l_{2}$ defined by $z \rho t=c^{t} z$. Here we generalize this result and show that a dynamical system $I$ on a separable metric space which has a globally asymptotically stable critical point $p$, can be embedded into the radial flow $\rho$ on $l_{2}$ if and only if $p$ is uniformly asymptotically stable. Moreover, if $\Pi$ can be embedded into $\rho$, then there is a locally compact subset $Y$ of $l_{2}$ such that $I I$ can be embedded into $\rho$ restricted to $Y$.

A dynamical system on a topological space $X$ is a continuous mapping $\Pi: X \times R \rightarrow X$ such that (where $x \Pi t=\Pi(x, t)$ )

(1) $x \Pi 0=x$ for every $x \in X$,

(2) $(x \Pi t) \Pi s=x \Pi(t+s)$ for every $x \in X$ and $s, t \in R$.

For $A \subset X$ and $B \subset R, A \Pi B$ will denote the set $\{x \Pi t: x \in A, t \in B\}$. In the special case $B=R$ we will write $C(A)$ instead of $A \Pi R$. An element $x \in X$ is called a critical point of $\Pi$ if $C(x)=\{x\}$. A subset $A$ of $X$ is invariant if $C(A)=A$. We will let $R^{+}$denote the nonnegative reals.

A compact subset $M$ of $X$ is called stable if for any neighborhood $U$ of $M$ there is a neighborhood $V$ of $M$ such that $V \Pi R^{+} \subset U$. A stable subset $M$ of $X$ is called

(i) asymptotically stable if for any neighborhood $U$ of $M$ and any $x \in X$, there is a $T \in R$ such that $x \Pi[T, \infty) \subset U$,

(ii) locally uniformly asymptotically stable if for any $x \in X-M$, there is a neighborhood $V$ of $x$ such that for any neighborhood $U$ of $M$ there exists $T \in R$ such that $V \Pi[T, \infty) \subset U$.

(iii) uniformly asymptotically stable if there is a neighborhood $U$ of $M$ such that for any neighborhood $V \subset U$ of $M$ there exists $T \in R$ such that $U \Pi[T, \infty) \subset V$.

A continuous function $L: R \rightarrow R^{+}$is called a Liapunov function for a subset $M$ of $X$ if

(i) $L(x)=0$ if and only if $x \in M$, 
(ii) $L(x \Pi t)<L(x)$ for every $x \in X-M$ and $0<t$,

(iii) for any neighborhood $U$ of $M$ there is an $\varepsilon>0$ such that $\varepsilon<L(x)$ whenever $x \notin U$,

(iv) for any $\varepsilon>0$ there is a neighborhood $V$ of $M$ such that $L(x)<\varepsilon$ whenever $x \in V$.

In [2] it is shown that a compact subset $M$ of a metric space is asymptotically stable if and only if there is a Liapunov function for $M$.

Throughout this paper $X$ will denote a separable metric space with metric $d$ and we will assume that $d(x, y) \leqq 1$ for every $x, y \in X$. For $x \in X$ and $\varepsilon>0$ the set $\{y \in X: d(x, y) \leqq \varepsilon\}$ will be denoted by $B(x, \varepsilon)$.

The set of all sequences $z=\left\{z_{1}, z_{2}, \cdots, z_{n}, \cdots\right\}$ of real numbers such that $\sum_{m=1}^{\infty} z_{m}^{2}$ converges is denoted by $l_{2}$. A norm can be defined on $l_{2}$ by $\|z\|=\left(\sum_{m=1}^{\infty} z_{m}^{2}\right)$. The origin in $l_{2}$ will be denoted by $\overline{0}$. Let $\rho$ denote the dynamical system on $l_{2}$ defined by $z \rho t=c^{t} z$, where $c \in(0,1)$.

Let $p$ be a uniformly asymptotically stable critical point of a dynamical system $\Pi$ on a separable metric space $X$. Let $U$ be a neighborhood of $p$ such that for any neighborhood $V \subset U$ of $p$ there is a $T>0$ so that $U \Pi[T, \infty) \subset V$.

Lemma 1. $C(x) \cap(X-U) \neq \varnothing$ for every $x \in X-\{p\}$.

Proof. Let $x \in X-\{p\}$. Since $C(x) \cap U=\varnothing$, we may assume that $x \in U$. Let $V$ be a positively invariant neighborhood of $p$ such that $x \notin V$ and $V \subset U$. Then $(x \Pi(-\infty, 0]) \cap V=\varnothing$. Let $T>0$ be such that $U \Pi[T, \infty) \subset V$. If $C(x) \cap(X-U)=\varnothing$, then $x \Pi(-\infty, T)=$ $(x \Pi(-\infty, 0]) \Pi T \subset V$ which is impossible since $(x \Pi(-\infty, 0]) \cap V=\varnothing$. It follows that $C(x) \cap(X-U) \neq \varnothing$ for every $x \in X-\{p\}$.

It is known that there is a Liapunov function $L$ for the uniformly aymptotically stable critical point $p,[2]$. Let $\lambda$ be a number in the range of $L$ such that $L^{-1}(\lambda) \subset U$ and set $S=L^{-1}(\lambda)$. It is easy to verify that $S$ is a section for $I I$ restricted to $X-\{p\}$. . Since $X$ is separable there is a countable dense subset $\left\{x_{n}\right\}$ of $S$. Define a countable number of continuous functions $f_{n}: S \rightarrow R^{n}$ by

$$
f_{n}(x)=d\left(x, x_{n}\right)
$$

where $d$ is a metric on $X$ such that $d(x, y) \leqq 1$ for all $x, y \in X$.

LEMMA 2. If $f_{n}(x) \leqq f_{n}(y)$ for every $n$, then $x=y$. 
Proof. Suppose that $x \neq y$. Set $r=d(x, y)$ and $B=\{z: d(z, y) \leqq$ $r / 4\}$. Since $\left\{x_{n}\right\}$ is dense in $S$ there is a $k$ such that $x_{k} \in B$. Then $f_{k}(y)=d\left(y, x_{k}\right) \leqq r / 4 \leqq 3 d\left(x, x_{k}\right) / 4<f_{k}(x)$. A similar argument shows that there is a $j$ such that $f_{j}(x)<f_{j}(y)$. The desired result follows directly.

LEMMA 3. The mapping $h: S \rightarrow l_{2}$ defined by

$$
h(x)=\left(f_{1}(x), \frac{1}{2} f_{2}(x), \cdots, \frac{1}{n} f_{n}(x), \cdots\right)
$$

is a homeomorphism of $S$ onto $h(S)$. Moreover, $\|h(x)\|^{2} \leqq \Pi^{2} / 6$ for every $x \in S$.

Proof. Let $x \in S$ and $\varepsilon>0$. For any $y \in B(x, \varepsilon)$, we have $d\left(x, x_{n}\right)-\varepsilon \leqq d\left(y, x_{n}\right) \leqq d\left(x, x_{n}\right)+\varepsilon$. Hence, for every $n$ we have $\left|f_{n}(x)-f_{n}(y)\right| \leqq \varepsilon$ whenever $y \in B(x, \varepsilon)$. This shows that $\left\{f_{n}\right\}$ is uniformly equicontinuous. It is now easy to show that $h$ is continuous. By Lemma 2 the mapping $h$ is one-to-one. Suppose there is a sequence $\left\{z_{i}\right\}$ in $S$ such that $h\left(z_{i}\right) \rightarrow h(z)$ for some $z \in S$. Then $f_{n}\left(z_{i}\right) \rightarrow f_{n}(z)$ for every $n$, i.e., $d\left(z_{i}, x_{n}\right) \rightarrow d\left(z, x_{n}\right)$ for every $n$. Let $\delta>0$ and choose $j$ so that $d\left(z, x_{j}\right)<\delta / 4$. Since $d\left(z_{i}, x_{j}\right) \rightarrow d\left(z, x_{j}\right)$ we have $d\left(z_{i}, z\right) \leqq$ $d\left(z_{i}, x_{j}\right)+d\left(z, x_{j}\right)<\delta$ for all $i$ sufficiently large. It follows that $z_{i} \rightarrow z$ so that $h^{-1}$ is continuous. Thus, $h$ is a homeomorphism of $S$ onto $h(S)$. Since $d(u, v) \leqq 1$ for every $u, v \in X$, we have $\|h(x)\|_{2}^{2} \leqq$ $\sum_{m=1}^{\infty} m^{-2}=\Pi^{2} / 6$ for every $x \in S$.

LEMMA 4. If $x, y \in S$ are such that $h(x)=h(y) \rho t$ for some $t \in R$, then $x=y$ and $t=0$.

Proof. Suppose that $h(x)=h(y) \rho t=c^{t} h(y)$ for some $t \in R$. Without loss of generality we may assume that $t \geqq 0$. Then $f_{n}(x)=$ $c^{t} f_{n}(y) \leqq f_{n}(y)$ for every $n$. By Lemma $2, x=y$. If $x=y$, clearly $t=0$.

Lemma 5. The mapping $H: X \rightarrow l_{2}$ defined by

$$
H(x)=\left\{\begin{array}{cl}
\overline{0} & \text { if } x=p, \\
h(x \Pi \Upsilon(x)) \rho(-\Upsilon(x)) & \text { if } x \in X-\{p\},
\end{array}\right.
$$

where $r: X-\{p\} \rightarrow R$ is a continuous mapping defined by $x \Pi r(x) \in S$, is a homeomorphism.

Proof. If $x \neq p$, then clearly $H(x) \neq \overline{0}=H(p)$. If $H(x)=H(y)$ with $x \neq p \neq y$, then $h(x \Pi \Upsilon(x)) \rho(-\Upsilon(x))=h(y \Pi \Upsilon(y)) \rho(-\Upsilon(y))$ so that 
$h(x \Pi \Upsilon(x))=h\left(y \Pi \Upsilon^{\prime}(y)\right) \rho(r(x)-r(y)) . \quad$ By Lemma $\quad 4 \quad$ we have $h(x \Pi r(x))=h(y \Pi r(y))$ and $r(x)=r(y)$. Since $h$ is one-to-one $x \Pi r(x)=y \Pi r(y)$. Hence, $x=y$ and $H$ is one-to-one. Since $h, \Pi, r$, and $p$ are continuous, $H$ is continuous on $X-\{p\}$. We will now show that $H$ is continuous at $p$. Let $\left\{z_{i}\right\}$ be any sequence in $X-\{p\}$ which converges to $p$. Since $p$ is stable there is a neighborhood $W$ of $\rho$ such that $W \Pi R^{+} \subset L^{-1}([0, \lambda / 2])$. Hence, $r\left(x_{i}\right) \leqq 0$ for all $i$ sufficiently large. It suffices to consider two cases: $r\left(z_{i}\right) \rightarrow-\infty$ and $r\left(z_{i}\right) \rightarrow t \leqq 0$. If $Y\left(z_{i}\right) \rightarrow-\infty$, then $H\left(z_{i}\right) \rightarrow \overline{0}$ since $\left\|h\left(z_{i} \Pi \Upsilon\left(z_{i}\right)\right)\right\| \leqq \Pi^{2} / 6$ for each $i$ and $\left\|H\left(z_{i}\right)\right\|=\left\|h\left(z_{i} \Pi r\left(z_{i}\right)\right) \rho\left(-r\left(z_{i}\right)\right)\right\|=c^{-r\left(z_{i}\right)}\left\|h\left(z_{i} \Pi r\left(z_{i}\right)\right)\right\| \rightarrow 0$. If $r\left(z_{i}\right) \rightarrow t$ then $0 \neq \lambda=L\left(z_{i} \Pi r_{i}\left(z_{i}\right)\right) \rightarrow L(p \Pi t)=L(p)=0$ which is impossible. Thus, $H$ is continuous. A short calculation shows that $H^{-1}(H(x))=h^{-1}[H(x) \rho r(x)] \Pi(-r(x))$ whenever $x \neq p$. Since $h^{-1}, H, \rho$, $r$, and $I I$ are continuous, $H^{-1}$ is continuous on $H(X)-\{\overline{0}\}$. Let $\left\{y_{i}\right\}$ be any sequence in $X-\{p\}$ such that $H\left(y_{i}\right) \rightarrow \overline{0}$. Since $H\left(y_{i}\right)=$ $c^{-r\left(y_{i}\right)} h\left(y_{i} \Pi r\left(y_{i}\right)\right)$ we must have either $r\left(y_{i}\right) \rightarrow-\infty$ or $h\left(y_{i} \Pi r\left(y_{i}\right)\right) \rightarrow \overline{0}$. If $h\left(y_{i} \Pi r\left(y_{i}\right)\right) \rightarrow \overline{0}$, then $d\left(y_{i} \Pi r\left(y_{i}\right), x_{n}\right) \rightarrow 0$ for every $n$, which is impossible. Hence $r\left(y_{i}\right) \rightarrow-\infty$. Recall that $S=L^{-1}(\lambda) \subset U$, where $U$ is a neighborhood of $p$ such that for any neighborhood $V \subset U$ of $p$ there is a $T$ so that $U \Pi[T, \infty) \subset V$. Then $y_{i}=\left(y_{i} \Pi \Upsilon\left(y_{i}\right)\right) \Pi\left(-r\left(y_{i}\right)\right) \in$ $\left.U I I-r\left(y_{i}\right), \infty\right)$. From our choice of $U$ and the fact that $r\left(y_{i}\right) \rightarrow-\infty$, we have $y_{i} \rightarrow p$. The continuity of $H^{-1}$ follows directly. $H$ is a homeomorphism of $X$ onto $H(X)$.

THEOREM 5. Let II be a dynamical system on a separable metric space $X$ which has a globally assymptotically stable critical point $p$. Let $c \in(0,1)$ and $\rho$ be the dynamical system on $l_{2}$ defined by $x \rho t=c^{t} x$. Then $\Pi$ can be embedded into $\rho$ if and only if $\rho$ is uniformly asymptotically stable.

Proof. Suppose that $I I$ can be embedded into $\rho$. Evidently the origin is uniformly asymptotically stable with respect to $\rho$. Since $\Pi$ is embedded into $\rho$, it is easy to show that $p$ is uniformly asymptotically stable. Now suppose that $p$ is uniformly asymptotically stable. In light of Lemma 4 it remains to show that $H(x \Pi t)=H(x) \rho t$. It is easy to show that $r(x \Pi t)=r(x)-t$. Hence,

$$
\begin{aligned}
H(x \Pi t) & =h((x \Pi t) \Pi r(x \Pi t)) \rho(-r(x \Pi t)) \\
& =h(x \Pi r(x)) \rho(-r(x)+t) \\
& =(h(x \Pi r(x)) \rho(-r(x))) \rho t \\
& =H(x) \rho t
\end{aligned}
$$

for every $x \neq p$ and $t \in R$. Clearly $H(p \Pi t)=H(p)=\overline{0}=\overline{0} \rho t$ for every $t \in R$. 
COROLlary 6. ([1]) Let $\Pi$ be a dynamical system on a locally compact space $X$. If $\Pi$ has a globally asymptotically stable critical point, then $\Pi$ can be embedded into $\rho$.

Lemma 7. Let $A$ be a compact subset of $l_{2}$ with $\overline{0} \notin A$. Then $(A \rho R) \cup\{\overline{0}\}$ is locally compact in the relative topology.

Proof. Since $A$ is a compact with $\overline{0} \notin A$, for any $N, \varepsilon>0$ there are $t_{1}, t_{2} \in R$ such that $\|A \rho t\|>N$ for $t<t_{1}$ and $\|A \rho t\|<\varepsilon$ for $t_{2}<t$. It easily follows that $A \rho R$ is locally compact since $A \rho B$ is compact whenever $B$ is a compact subset of $R$. Next we will show that $\left(A \rho R^{+}\right) \cup\{\overline{0}\}$ is a compact neighborhood of $\overline{0}$ in $A \rho R$. Clearly $A \rho R^{+}$ is a neighborhood of $\overline{0}$ in $(A \rho R) \cup\{\overline{0}\}$. Let $\left\{x_{i}\right\}$ and $\left\{t_{i}\right\}$ be any sequences in $A$ and $R^{+}$respectively. Without loss of generality we may assume that there is an $x \in A$ such that $x_{i} \rightarrow x$. If $\left\{t_{i}\right\}$ has an accumulation point $t$, then $x \rho t$ is an accumulation point of $\left\{x_{i} \rho t_{i}\right\}$. If $t_{i} \rightarrow \infty$, then $x_{i} \rho t_{i} \in A \rho t_{i} \rightarrow \overline{0}$. It follows that any sequence in $\left(A \rho R^{+}\right) \cup\{\overline{0}\}$ has an accumulation. Hence, $\left(A \rho R^{+}\right) \cup\{\overline{0}\}$ is compact. The desired result follows immediately.

THEOREM 8. Let $\Pi$ be a dynamical system on a separable metric space $X$ which has a globally asymptotically stable critical point $p$. Let $c \in(0,1)$ and $\rho$ be the dynamical system on $l_{2}$ defined by $x \rho t=c^{t} x$. If II can be embedded into $\rho$, then there exists a locally compact subset $Y$ of $l_{2}$ such that $I I$ can be embedded into $\rho$ restricted to $Y$.

Proof. Let the notation be as before. Evidently $h(S)$ is a subset of the Hilbert cube, $T=\left\{x \in l_{2}: x=\left(x_{1}, x_{2}, \cdots, x_{n}, \cdots\right)\right.$ with $\left|x_{n}\right| \leqq n^{-1}$ for each $n\}$, which is a compact subset of $l_{2}$. Since $S=L^{-1}(\lambda)$, the section $S$ is a closed subset of $X$ with $p \notin S$. Hence $\overline{0} \notin h(S)$. Since

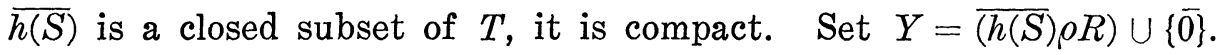
By Lemma 7, $Y$ is a locally compact subset of $l_{2}$. Clearly $H(X) \subset Y$. The desired result follows directly.

\section{REFERENCES}

1. R. C. McCann, Asymptotically stable dynamical systems are linear, Pacific J. Math., $8 \mathbf{1}$ (1979), 475-479.

2. - On the asymptotic stability of a compact and parallelizability of its region of attraction, to appear in Funkcialaj Ekracioj.

Received June 1, 1979.

Mississippi State University

Mississippi State, MS 39762 



\section{PACIFIC JOURNAL OF MATHEMATICS}

\section{EDITORS}

DONALD BABBITT (Managing Editor)

University of California

Los Angeles, CA 90024

Hugo RossI

University of Utah

Salt Lake City, UT 84112

C. C. MOORE and ANDREW OGG

University of California

Berkeley, CA 94720

\section{J. DugunduI}

Department of Mathematics

University of Southern California

Los Angeles, CA 90007

R. Finn and J. Milgram

Stanford University

Stanford, CA 94305

\section{ASSOCIATE EDITORS}
E. F. BeCKenBACH
B. H. NeumanN
F. WOLF
K. YosHIDA

\section{SUPPORTING INSTITUTIONS}

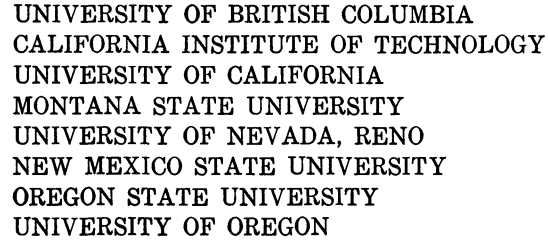

UNIVERSITY OF BRITISH COLUMBIA CALIFORNIA INSTITUTE OF TECHNOLOGY UNIVERSITY OF CALIFORNIA

MONTANA STATE UNIVERSITY

UNIVERSITY OF NEVADA, RENO

NEW MEXICO STATE UNIVERSITY

OREGON STATE UNIVERSITY UNIVERSITY OF OREGON

\author{
UNIVERSITY OF SOUTHERN CALIFORNIA \\ STANFORD UNIVERSITY \\ UNIVERSITY OF HAWAII \\ UNIVERSITY OF TOKYO \\ UNIVERSITY OF UTAH \\ WASHINGTON STATE UNIVERSITY \\ UNIVERSITY OF WASHINGTON
}

The Supporting Institutions listed above contribute to the cost of publication of this Journal, but they are not owners or publishers and have no responsibility for its content or policies.

Mathematical papers intended for publication in the Pacific Journal of Mathematics should be in typed form or offset-reproduced, (not dittoed), double spaced with large margins. Please do not use built up fractions in the text of the manuscript. However, you may use them in the displayed equations. Underline Greek letters in red, German in green, and script in blue. The first paragraph or two must be capable of being used separately as a synopsis of the entire paper. Please propose a heading for the odd numbered pages of less than 35 characters. Manuscripts, in triplicate, may be sent to any one of the editors. Please classify according to the scheme of Math. Reviews, Index to Vol. 39. Supply name and address of author to whom proofs should be sent. All other communications should be addressed to the managing editor, or Elaine Barth, University of California, Los Angeles, California, 90024.

50 reprints to each author are provided free for each article, only if page charges have been substantially paid. Additional copies may be obtained at cost in multiples of 50 .

The Pacific Journal of Mathematics is issued monthly as of January 1966. Regular subscription rate: $\$ 84.00$ a year (6 Vols., 12 issues). Special rato: $\$ 42.00$ a year to individual members of supporting institutions.

Subscriptions, orders for numbers issued in the last three calendar years, and changes of address shoud be sent to Pacific Journal of Mathematics, P.O. Box 969, Carmel Valley, CA 93924, U.S.A Old back numbers obtainable from Kraus Periodicals Co., Route 100, Millwood, NY 10546.

PUBLISHED BY PACIFIC JOURNAL OF MATHEMATICS, A NON-PROFIT CORPORATION

Printed at Kokusai Bunken Insatsusha (International Academic Printing Co., Ltd.). 8-8, 3-chome, Takadanobaba, Shinjuku-ku, Tokyo 160, Japan.

Copyright (C) 1980 by Pacific Jounal of Mathematics Manufactured and first issued in Japan 


\section{Pacific Journal of Mathematics \\ Vol. 90, No. $2 \quad$ October, 1980}

Frank Hayne Beatrous, Jr., Hölder estimates for the $\bar{\partial}$ equation with a support condition ..................................... 249

Charles L. Belna, Michael Jon Evans and Paul Humke, Planar continua

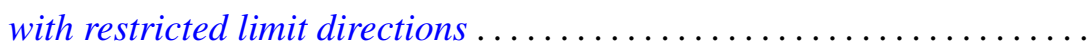

Leon Brown and Takashi Ito, Classes of Banach spaces with unique isometric preduals................................. 261

V. K. Deshpande, Completions of Noetherian hereditary prime rings ..... . 285

Deepak Dhar, Asymptotic enumeration of partially ordered sets . . . . . . . 299

Zeev Ditzian, On interpolation of $L_{p}[a, b]$ and weighted Sobolev

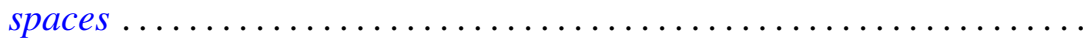

Andrew George Earnest, Congruence conditions on integers represented by

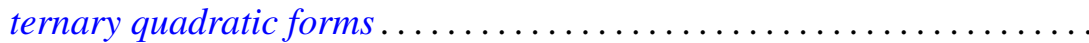

Melvin Faierman, Bounds for the eigenfunctions of a two-parameter system of ordinary differential equations of the second order ..............

Hector O. Fattorini, Vector-valued distributions having a smooth

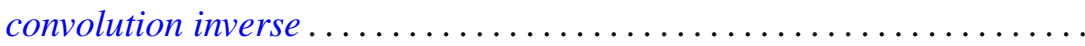

Howard D. Fegan, The spectrum of the Laplacian on forms over a Lie

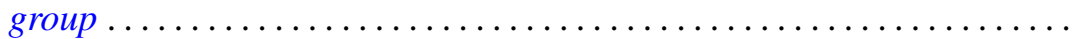

Gerald Leonard Gordon, On the degeneracy of a spectral sequence associated to normal crossings..

S. Madhavan, On bisimple weakly inverse semigroups ... 397

Françoise Mathot, On the decomposition of states of some

Roger McCann, Embedding asymptotically stable dynamical systems into radial flows in $l_{2}$

Michael L. Mihalik, Ends of fundamental groups in shape and proper homotopy...............................

Samuel Murray Rankin, III, Boundary value problems for partial functional differential equations .

Randy Tuler, Arithmetic sums that determine linear characters on $\Gamma(N)$

Jeffrey D. Vaaler, On linear forms and Diophantine approximation ..

G. P. Wene, Alternative rings whose symmetric elements are nilpotent or a right multiple is a symmetric idempotent. . 